\title{
Rare Presentation of Pulmonary Embolism Associated with PCP in a 28-Year-Old Man who was not known to be infected with HIV Before
}

\author{
Nasser Al-Shekaili,(a) Ahmed Nada,(b) Yousif A. Hamad ,(c) \\ (a) Pulmonology consultant - Ibri Hospital - Oman. \\ (b) General medicine - Ibri Hospital - Oman. \\ (c) General medicine - Ibri Hospital - Oman.
}

Abstract

\section{$>$ Introduction} Human

Viruses (HIV) commonly presented with acute seroconversion symptoms or opportunistic infections from immunosuppression, but first presentation of HIV with pulmonary embolism associated with active Pneumocystis pneumonia (PCP) is very rare.

\section{$>$ Case presentation}

A 28-year-old man presented with history of fever and cough associated with dyspnoea over 8 weeks and gradually worsen till maximised 2 week prior to admission. he did not improved inspite of antibiotics for suspected pneumonia. Found to be HIV positive with opportunistic infection. Computed Tomography Pulmonary Angiogram (CTPA) confirmed the presence of pulmonary embolism. He was treated successfully with anticoagulants, steroids, and antibiotics. discharged on base of clinical and radiological improvement.

\section{Conclusion}

Pulmonary embolism can be the first presentation of a newly diagnosed with HIV patient.

The similar features of both viral pneumonia and subacute pulmonary embolism can lead to delay diagnosis, especially in the era of covid-19 pandemic infection.

Keywords:- Dyspnoea, HIV, Immunosuppression, Pneumocystis pneumonia, Pulmonary embolism.

\section{INTRODUCTION}

HIV is a virus that attacks the body's immune system, specifically the CD4 cells. This ongoing damage to the immune system makes it weaker to fight against infections specifically the opportunistic infections such as Pneumocystis jiroveci pneumonia (PCP). PCP is a potentially life-threatening infection that occurs in immunocompromised individuals, especially in those with HIV. Infections (specifically pneumonia, urinary tract infection, and HIV) are considered as moderate risk factor for pulmonary embolism (PE) [1] .HIV infection carried a risk of hypercoagulation [2], but incidence of acute or subacute PE is rare [3] and usually seen in the advanced stage of the disease [4] .Recently published researches recommends for further studies to better understand the role of HIV in the occurrence of thromboembolic disease [5] . PE as a first presentation in a non-diagnosed HIV is very rare; a PubMed search revealed only 3 cases reported previously but none of them were associated with PCP [6 ] .We describe a first case who presented with acute PE and PCP, who was subsequently diagnosed as having HIV infection.

\section{CASE PRESENTATION}

A 28-year-old gentleman with no past history of medical illnesses presented with a 2 months history of dry cough, mild grade fever . in the beginning he ignored his features and did not seek any medical help till his symptoms worsened with productive cough and frequent fever.

He was seen in his primary health care institute 2 weeks prior to admission and was assumed as covid-19 suspected case, but the test came negative for SARS COV-2-RNA, for that was discharged on oral amoxicillin as pneumonia wilt low risk.

Following that he was not feels any improvement but his symptoms rather increased in matter of dyspnea which was exertional mainly, productive cough and continuous pyrexia. He was referred to our hospital as a non-resolved pneumonia.

During history taking he denied any chronic medical illnesses. There was no contact to sick patient or animals. No family history of haematological diseases. He lost about $10 \mathrm{Kg}$ of his weight in last 2 months. His weight during admission was $40 \mathrm{~kg}$.

There was no history of joint pain or skin rash.

He was initially isolated to rule out covid-19.

On examination he was fully conscious, oriented, tachypnoeic (32 breaths per minute), desaturated with spo2 $89 \%$ on room air, tachycardic with heart rate: 150 beat per minute and had high grade fever (temp: $39.6 \mathrm{C}$ ). his blood pressure was $140 / 75$. 
On auscultation, few crackles were heard in left lung base and the heart sounds were regular. Cardiac and abdominal examination did not reveal any abnormalities.

Due to COVED-19 pandemic another sample of (SARS-COV-2 RNA) was collected which came negative again.

His initial laboratory investigations revealed raised CRP: 337 but his complete blood picture was acceptable without leucocytosis. His routine test such as renal function, liver function and electrolytes were all with normal levels. The initial blood gases showed a picture of hypoxemia with low arterial carbon dioxide consistent with type 1 respiratory failure pattern $\left(\mathrm{PH} 7.46, \mathrm{PCO}_{2-}\right.$ $\left.27 \mathrm{mmHg}, \mathrm{PO}_{2}-42 \mathrm{mmHg}, \mathrm{HCO}_{3}-18.7 \mathrm{mEq} / \mathrm{L}\right)$.

Hepatitis C Virus (HCV) antibodies and Hepatitis B surface antigen (HBsAg) were negative.

An initial electrocardiogram showed a sinus tachycardia (115 bpm) and right axis deviation. On the chest $\mathrm{x}$-ray film, there was bilateral patchy infiltration more on the left upper and lower lobes. [Figure -1]

3 samples of sputum for acid fast bacilli (AFB) was negative .Mantoux test was negative. Mycobacterium Tuberculosis polymerase chain reaction (MTB PCR) sputum negative. MTB PCR from Broncho-alveolar lavage (BALL) also negative. Sputum culture also came negative.

Transthoracic echocardiogram revealed a normal cardiac champers, good left ventricular (LV) systolic function with left ventricular ejection fraction (LVEF) : $82 \%$. RT side not dilated with good RT ventricular function. No significant valvopathy. No significant pulmonary arterial hypertension (estimated RVSP/PASP: $30-35 \mathrm{mmHg})$.

He remained feverish with low grade intermittent fever and had mild exertional dyspnoea.

The post- intravenous contrast chest CT was done and the findings were reported as: Relatively reduced left lung volume, widespread ill-defined patchy opacities with more peripheral than central distribution, part of them showing crazy paving and ground glass pattern and they are seen involving nearly all lobes, relatively sparing lung apex. Related mild bronchiectatic changes seen. Also, right lung shows fewer peripheral opacities with area of lower lobe consolidation collapse with air bronchogram. No obvious pulmonary mass or cavities, free small mediastinal, no plural effusion, calcification, or emphysema. The conclusion was described pulmonary opacities, viral pneumonia still has to be considered. Note: although pulmonary angiography was not in this scan protocol but still there is ill defined suspicious hypodense area mainly at the right main bronchus distally could represent thrombosis vs flow related artifacts.
Bronchoscopy done which revealed : diffuse hyperaemic mucus of both sites. BALL taken from left lower lobe (LLL) and lingulea : Negative for fungus and AFB. BALL culture revealed Klebsiella pneumoniae .

The retroviral infection confirmed with positive (Elisa) 2 times, positive Western blot and very high HIV RNA Viral load reaching 1,130,000.

\section{BALL Cytology showed : PCP.}

D-dimers were markedly elevated at $19.51 \mathrm{mg} / \mathrm{L}$ (Reference range: $0.1-0.5$ ).

CT pulmonary angiogram (CTPA) revealed right lower lobe (RLL) branch pulmonary arteries embolism: Filling defect at the lower lobe branch of the right pulmonary artery. Pulmonary trunk, right and left pulmonary arteries and rest of their branches have normal calibre and normal contrast enhancement, no obvious filling defect. [Figure -3]

\section{Therapeutic anticoagulation started.}

The working diagnosis at this point was subacute pulmonary embolism (PE), associated with PCP and klebsiella pneumonia in a newly diagnosed HIV.

He was commenced on antibiotics; amoxicillin with clavulanic acid 1.2 gram three times per day , Clarithromycin $500 \mathrm{mg}$ two times per day and Oseltamivir $75 \mathrm{mg}$ two times per day for 4 days, but still he was febrile, so antibiotics upgraded to Tazocin $4.5 \mathrm{~g}$ QID. He received Tazocin for 13 days.

Commenced on anti - PCP regimen with cotrimoxazole and prednisolone.

The patient received high-flow oxygen at $8 \mathrm{~L} / \mathrm{min}$ via face mask, low-molecular weight heparin (enoxaparin $80 \mathrm{mg}$ twice daily), warfarin (5 mg once daily).

The patient improved dramatically after starting these medications. Highly active anti-retroviral therapy (HAART) launched after 2 weeks of treating infection.

he was no longer suffering from exertional dyspnoea, his $\mathrm{SaPO}_{2}$ was $96 \%$ on ambient air, the lung fields were clear on auscultation, and there was a reduction in his respiratory rate to $24 / \mathrm{min}$.

He was discharged on day 24 in a good condition with the following medications: Cotrimoxazole tablet $960 \mathrm{mg}$ given $1920 \mathrm{mg}$ twice per day (BID), Prednisolone tablet 20 $\mathrm{mg}$ BID, Warfarin $5 \mathrm{mg}$ od, Efavirenz $600 \mathrm{mg}+$ Emtricitabine $200 \mathrm{mg}+$ Tenofovir Disoproxil $300 \mathrm{mg}$ tablet $(1100 \mathrm{~g} / 1$ tablet $)$ at night.

Results of the investigations performed are shown in [Table- 1] below. 


\section{DISCUSSION}

The dilemma in this patient that he came with a respiratory features during cvid-19 pandemic, so the priority was to exclude that. The similarity between PE and viral pneumonia in clinical presentation are well known [7 ].

The second difficulty that the coexistence of PE and PCP in a newly diagnosed HIV often poses a diagnostic dilemma (6) specifically during Covid-19 outbreak .

Generally, the incidence of PE among HIV infected patients are uncommon. In one retrospective review of 3792 HIV case records published in Feb 1999 , only 10 $(0.26 \%)$ had PE [8].

Few cases have been reported of first presentation of new HIV infection with acute or sub-acute PE [6].

One study published in July 2013 described only two cases who presented with acute $\mathrm{PE}$ and subsequently diagnosed as having HIV infection. A Medline search done by authors revealed only one case reported before their study [6].

Our patient presented with features mimicking an acute pulmonary condition. At the primary health care before he presented to our secondary institution, he was treated as a case of pneumonia and suspected Covid-19 in view of respiratory manifestations. However, he did not respond to several days' treatment with oral amoxicillin. .He received also injectable antibiotics without significant clinical improvement. Furthermore, due to his persistent symptoms and the chest $\mathrm{x}$-ray picture, a diagnosis of pulmonary tuberculosis was also suspected, for which he thoroughly investigated and again all tests came negative and TB excluded.

Due to published data for the possibility of false negative of the initial covid-19 test we did another test [9 ].

The poor response to anti-biotics, negative results for a possible tuberculous cause, and an initial radiological suspension of viral pneumonia vs PE led us to entertain the possibility of associated pulmonary embolism.

The dilemma in managing our patient was isolating him as a suspected Covid-19 in view of similar presentation and radiological picture and suspected TB. However, the patient was closely followed up, with routine vital signs and laboratory tests. We had a high index of suspicion for covid-19 and TB in this patient before alternative diagnosis was sought.
After release of positive initial HIV antibodies, we took up further step to confirm the diagnosis. In some instances, a false-positive HIV test may occur by western blot. For this reason, the HIV-positive result in this patient was confirmed by DNA PCR. In early HIV infection, which is a period of rapid viral replication and infection of CD4 T cells, the viral RNA level is typically very high (eg, $>100,000$ copies $/ \mathrm{mL}$ ) and the CD4 cell count can drop transiently. Opportunistic infections can rarely occur during this transient CD4 lymphopenia [10] .

Pneumocystis pneumonia (PCP) remains one of the leading causes of opportunistic infection in HIV-infected individuals. The risk factors include not receiving ART, a CD4 cell count less than 200 cells/microL, previous episodes of PCP, oral thrush, recurrent bacterial pneumonia, unintentional weight loss, and higher plasma HIV RNA levels.

$\mathrm{PE}$ is very rare as first presentation in a newly diagnosed HIV. thromboembolic complication known to occur in late stages of HIV. The features which supported the possibility of PE was a HR >100 bpm, hypoxia and hypocapnia, high d-dimers. But there was a possible alternative diagnosis to explain illness which was viral pneumonia and Covid-19. In addition, a positive d-dimer test is not a very reliable marker because it is not specific for PE. Many factors, including Covid-19, are known to be associated with a positive d-dimer test [11].

Our patient showed a dramatic response after Cotrimoxazole and prednisolone for PCP and anticoagulant for PE. The response indicated by clinical improvement of fever, exertional dyspnoea and radiologically by clear chest x-ray. [Figure -2]

In conclusion: the pulmonary embolism should be expected as a presenting feature of undetected HIV infection. During laboratory workup for underline cause of PE , HIV infection should be on the list .Pneumonia can mask and therefore delay the diagnosis of PE specially during viral pandemic such as covid-19.

\section{ACKNOWLEDGEMENTS}

We are indebted to the patient for this understanding and written consent to allow us to publish the present data.

We are also indebted to Dr. Rashid Al-Megbali for his precious opinion on the manuscript.

\section{Ethics:}

The patient has given written informed consent for the publication of this case report and any accompanying images. A copy of the written consent is ready for the review by the editor-in-chief of this journal. 
Disclosure:

The authors have no conflicts of interest to declare.

\section{Funding:}

The authors have no funding relevant to this study from any sponsor. the preparation of data and the manuscript was self-funded.

\section{Authors' contributions}

Drs Nasser, Ahmed, and Yousif were responsible for clinical management of the patient, collection, and interpretation of clinical data. All participated in the discussion of the present case and contributed to the drafting of the manuscript.

\section{Abbreviations}

CT: computed tomography

DNA PCR: deoxyribonucleic acid polymerase chain reaction

ECG: electrocardiogram

HAART: highly active anti-retroviral therapy

HIV: human immunodeficiency virus

PCP: Pneumocystis jiroveci pneumonia

PE: pulmonary embolism

HR: heart rate

\section{REFERENCES}

[1]. 2019 ESC Guidelines for the diagnosis and management of acute pulmonary embolism https://academic.oup.com/eurheartj/article/41/4/543/5 556136

[2]. Swati Khare, Rashmi Kushwaha, Ashutosh Kumar, Vimala Venkatesh, Himanshu D Reddy, Mili Jain, Mohd Yusuf, Uma Shankar Singh. Prothrombotic state in HIV: A study on protein C, protein S, homocysteine and correlation with CD4 counts.

http://www.ijmm.org/article.asp?issn=0255-

0857; year $=2018$; volume $=36$; issue $=2 ;$ spage $=201$; epag $\mathrm{e}=206$; aulast $=$ Khare

[3]. S J Howling 1, P J Shaw, R F Miller (Acute Pulmonary Embolism in Patients With HIV Disease) 1999

Feb. https://pubmed.ncbi.nlm.nih.gov/10448338/?from_ter $\mathrm{m}=$ pulmonary+embolism+in+patient+with+HIV\&fro m_sort=\&from_pos $=6$
[4]. Alejandro Alvaro-Meca and his colleagues (Trends in Pulmonary Embolism in Patients Infected With HIV During the Combination Antiretroviral Therapy Era in Spain: A Nationwide PopulationBased Study) $2018 \quad$ Aug https://pubmed.ncbi.nlm.nih.gov/30108235/?from_ter $\mathrm{m}=$ pulmonary+embolism+in+patient+with+HIV\&fro $\mathrm{m} \_$sort $=\&$ from_pos $=1$

[5]. Frédéric Nogbou Ello and colleagues [Thromboembolic Manifestations in 36 HIV infected Patients in West Africa] Pan Afr Med J 2018

Dec https://pubmed.ncbi.nlm.nih.gov/31447982/?from_ter $\mathrm{m}=$ pulmonary+embolism+in+patient+with+HIV\&fro $\mathrm{m} \_$sort $=\&$ from_pos $=2$

[6]. S Patra , C M Nagesh, B Reddy, B C Srinivas, C N Manjunath, M Hegde Acute Pulmonary Embolism Being the First Presentation of Undetected HIV Infection: Report of Two Cases. 2013 Jul .https://pubmed.ncbi.nlm.nih.gov/23970756/

[7]. Vivek Nagaraja and colleagues ( Pulmonary Embolism Mimicking Pneumonia in a HIV $\begin{array}{llll}\text { Patient) } & 2010 & \text { Jun }\end{array}$ https://pubmed.ncbi.nlm.nih.gov/20589218/

[8]. Howling SJ, Shaw PJ, Miller RF (Acute pulmonary embolism in patients with HIV disease). Feb 1999 https://europepmc.org/article/PMC/PMC1758180

[9]. Steven Woloshin and colleagues: (False Negative Tests for SARS-CoV-2 Infection - Challenges and Implications)

https://www.nejm.org/doi/full/10.1056/NEJMp20158 97

[10]. UpToDate: (acute-and-early-hiv-infection-clinicalmanifestations-and-diagnosis)

https://www.uptodate.com/contents/acute-and-earlyhiv-infection-clinical-manifestations-anddiagnosis?search=diagnosis\%20of\%20hiv\&sectionRa $\mathrm{nk}=2$ \&usage_type $=$ default\&anchor $=$ H18410843\&sou rce $=$ machineLearning $\&$ selectedTitle $=1 \sim 150 \&$ display _rank=1\#H18410843

[11]. Drs. Morayma Reyes Gil, Aggie Lee, Nigel Key, Dan Sabath, Cindy Leissinger, Oksana Volod, Geoff Wool , Lisa Baumann Kreuziger: (COVID-19 and Ddimer: Frequently Asked Questions) https://www.hematology.org/covid-19/covid-19-andd-dimer 


\section{FIGURES AND TABLES}

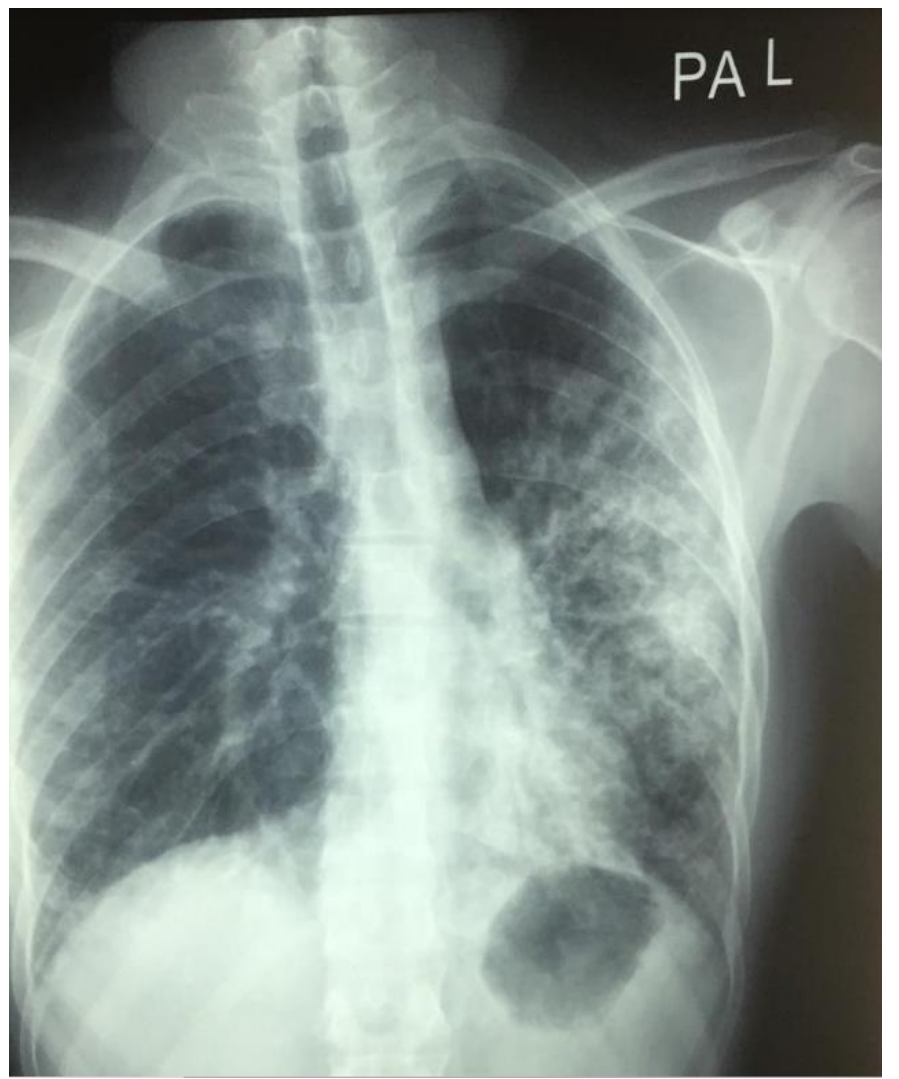

Fig 1:- Chest X-ray on presentation showing bilateral lung infiltration , more on left side.

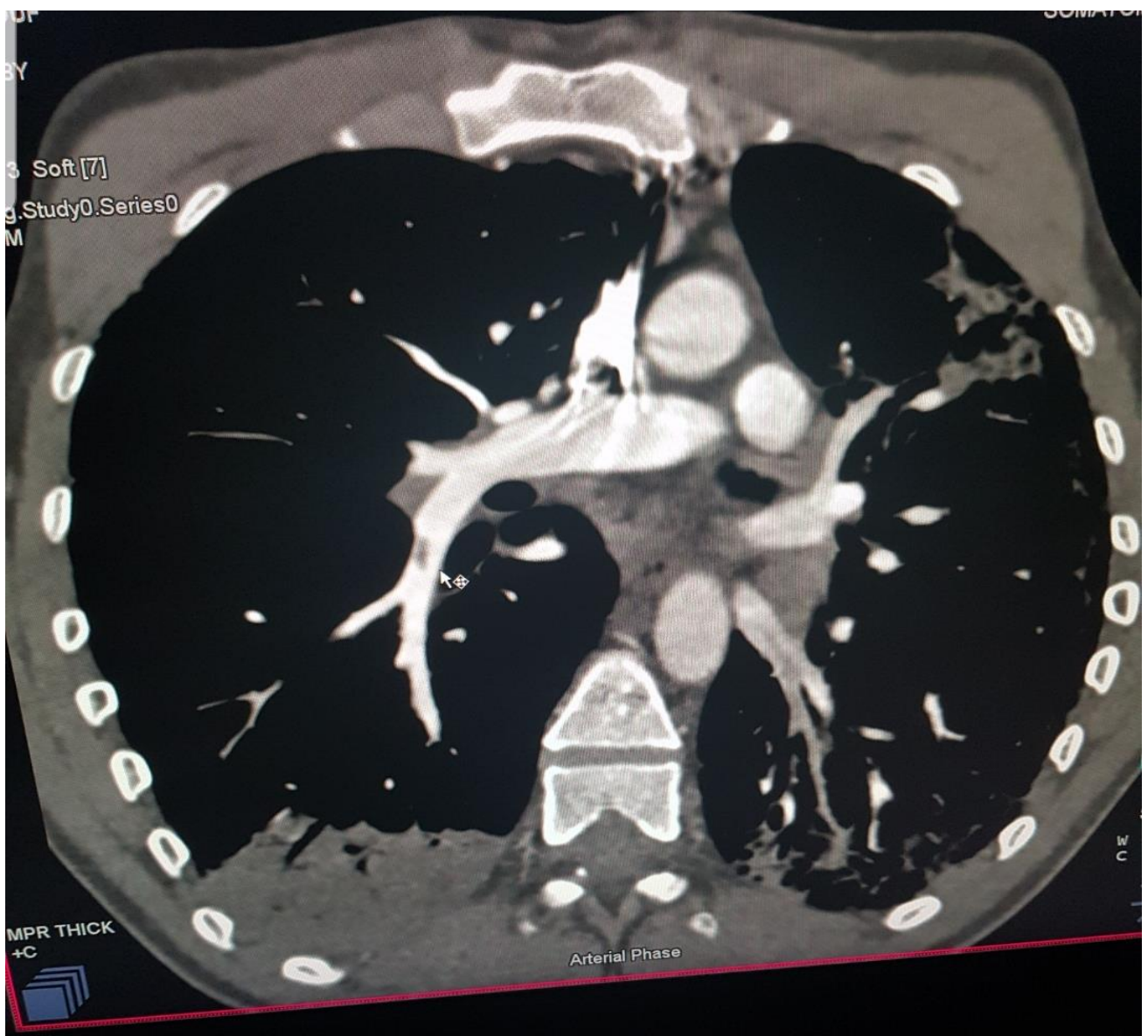

Fig 2:- CT pulmonary angiogram (CTPA) showing right lower lobe (RLL) branch pulmonary arteries embolism 


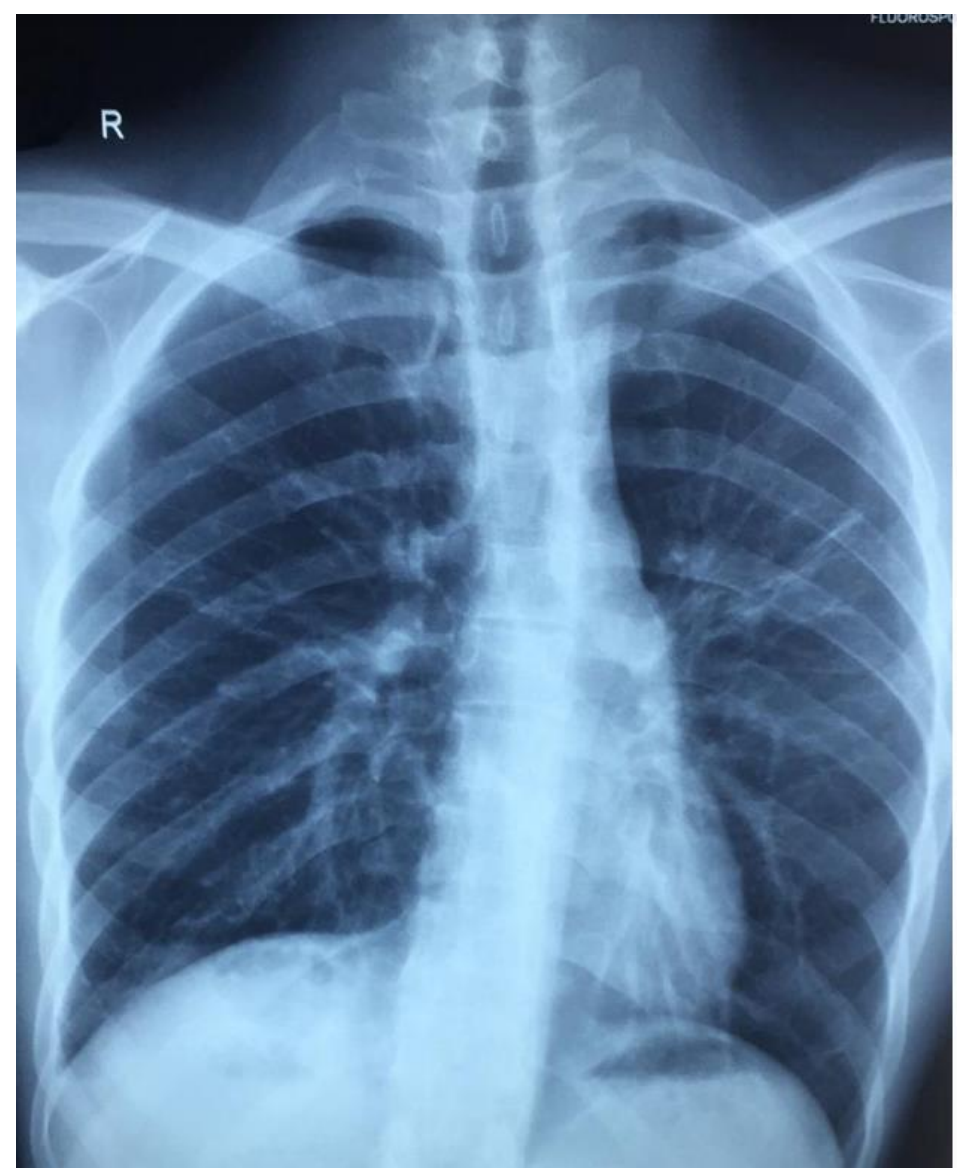

Fig 3:- chest x-ray before discharge showing much improvement of lung infiltration

\begin{tabular}{|c|c|c|c|}
\hline Test & Result & Reference range & Date per day of admission \\
\hline Sputum culture & Normal flora & 0 & 1 \\
\hline SARS-COV-2 RNA PCR & Not detected & & 1 \\
\hline Ferritin & $1436 \mathrm{ug} / \mathrm{L}$ & $30-400 \mathrm{ug} / \mathrm{L}$ & \\
\hline $\begin{array}{c}\text { ESR (Erythrocyte } \\
\text { sedimentation Rate) }\end{array}$ & 130 & & 1 \\
\hline \multirow[t]{6}{*}{ LFT (Liver function test) } & Total bilirubin: 11.24 umpl/L & (0- 20) umpl/L & 1 \\
\hline & $\begin{array}{l}\text { ALT (Alanine transaminase ): } 44.93 \\
\text { U/L }\end{array}$ & $(0-40) \mathrm{ug} / \mathrm{L}$ & 1 \\
\hline & $\begin{array}{l}\text { ALP (Alkaline phosphatase): } \\
109.73 \mathrm{U} / \mathrm{L}\end{array}$ & $(40-150) \mathrm{U} / \mathrm{L}$ & 1 \\
\hline & Total protein: $71.13 \mathrm{~g} / \mathrm{L}$ & $(60-80) \mathrm{g} / \mathrm{L}$ & 1 \\
\hline & Albumin: $26 \mathrm{~g} / \mathrm{L}$ & $(35-50) \mathrm{g} / \mathrm{L}$ & 1 \\
\hline & Globulin: $44.58 \mathrm{~g} / \mathrm{L}$ & & 1 \\
\hline \multirow[t]{3}{*}{ RFT (Renal function test) } & Urea: $5.17 \mathrm{mmol} / \mathrm{L}$ & $(2.5-6.7) \mathrm{mmol} / \mathrm{L}$ & 1 \\
\hline & Serum creatinine: $71.00 \mathrm{mmol} / \mathrm{L}$ & $(45-100) \mathrm{mmol} / \mathrm{L}$ & \\
\hline & e-GFR (MDRD): > 90 ML/MIN & $>90 \mathrm{ML} / \mathrm{MIN}$ & 1 \\
\hline Electrolytes & $\begin{array}{l}\text { Sodium : } 136.63 \mathrm{mmol} \\
\text { Potassium: } 4.74 \mathrm{mmol} / \mathrm{L}(3.5-5)\end{array}$ & $\begin{array}{l}(137-148) \mathrm{mmol} \\
(3.5-5) \mathrm{mmol}\end{array}$ & 1 \\
\hline CRP (C Reactive protein ) & 337.53 & $0-5 \mathrm{mg}$ per liter & 1 \\
\hline \multirow[t]{5}{*}{ CBC (Complete blood count) } & Haemoglobin in blood: $11.4 \mathrm{~g} / \mathrm{dl}$ & $(11.5-15.5) \mathrm{g} / \mathrm{dl}$ & 1 \\
\hline & $\begin{array}{l}\text { White blood cells in blood: } 8.34 \\
10 * 3 / \mathrm{ul}\end{array}$ & $(2.2-10) 10 * 3 / \mathrm{ul}$ & 1 \\
\hline & Platelet: $154.610 * 3 / \mathrm{ul}$ & $(140-400) 10 * 3 / \mathrm{ul}$ & 1 \\
\hline & Neutrophils: $6.8 \quad 10 * 3 / \mathrm{ul}$ & $(1-5) 10 * 3 / \mathrm{ul}$ & 1 \\
\hline & Lymphocytes: $0.56 \quad 10 * 3 / \mathrm{ul}$ & $(1.2-4) 10 * 3 / \mathrm{ul}$ & 1 \\
\hline
\end{tabular}


ISSN No:-2456-2165

\begin{tabular}{|c|c|c|c|}
\hline & $\begin{array}{l}\text { Eosinophils: } 0.01 \\
10 * 3 / \mathrm{ul}\end{array}$ & $(0.1-0.5) 10 * 3 / \mathrm{ul}$ & 1 \\
\hline & $\begin{array}{c}\text { Monocytes: } 0.88 \\
10 * 3 / \mathrm{ul}\end{array}$ & $(0.2-0.6) 10 * 3 / \mathrm{ul}$ & 1 \\
\hline & $\begin{array}{c}\text { Basophils: } 0.05 \\
10 * 3 / \mathrm{ul}\end{array}$ & $(0-0.2) 10 * 3 / \mathrm{ul}$ & 1 \\
\hline INR & 3.86 & & 20 \\
\hline Serum Sodium & $137 \mathrm{mmol} / \mathrm{l}$ & $137-148 \mathrm{mmol} / \mathrm{l}$ & 2 \\
\hline Serum Potassium & $3.7 \mathrm{mmol} / 1$ & $3.5-5 \mathrm{mmol} / \mathrm{l}$ & 2 \\
\hline Cross -linked D- dimer & $19.5 \mathrm{mg} / \mathrm{l}$ & $(0.1-0.5) \mathrm{mg} / \mathrm{l}$ & 13 \\
\hline Urine $\mathrm{c} / \mathrm{s}$ & No bacterial growth & & 11 \\
\hline Blood c/s & No bacterial growth & & 11 \\
\hline Mycobacterial TB - PCR & MTBC not detected & & 11 \\
\hline Bronchial lavage cytology & $\begin{array}{l}\text { Pneumocystis jirovecii organisms } \\
\text { are seen in the GMS stain. } \\
\text { Negative for malignant cells }\end{array}$ & & 6 \\
\hline Bronchial lavage culture & $\begin{array}{c}\text { Heavy growth of Klebsiella } \\
\text { pneumoniae, sensitive for } \\
\text { ampicillin, cefuroxime, } \\
\text { ciprofloxacin, gentamycin, } \\
\text { pipracillin + tazobac, trimethoprim } \\
+ \text { sulfame }\end{array}$ & & 6 \\
\hline Bronchial lavage $-\mathrm{ZN}$ stain & No AFB seen & & 6 \\
\hline $\begin{array}{c}\text { Bronchial lavage }-\mathrm{KOH} \\
\text { prepa }\end{array}$ & No fungal elements seen & & 6 \\
\hline HIV -1 RNA viral load & $1,130,000$ copies $/ \mathrm{ml}$ & & 4 \\
\hline Lymphocyte subset analysis & T-helper CD4+ count : 121 & & 2 \\
\hline $\begin{array}{l}\text { Toxoplasma ELISA }(\operatorname{IgM}+ \\
\text { IgG) }\end{array}$ & negative & & 2 \\
\hline $\begin{array}{l}\text { Cytomegalovirus serology } \\
\text { panel }\end{array}$ & $\begin{array}{l}\text { Ab. IgM : not detected } \\
\text { Ab. IgG: detected }\end{array}$ & & 2 \\
\hline HIV I\&II antibodies & Positive & & 2 \\
\hline Anti- HCV & Non-reactive & & 2 \\
\hline Hepatitis B basic profile & HBsAg: Non-reactive & & 2 \\
\hline Sputum culture & Normal flora & & 2 \\
\hline Sputum AFB stain (ZN stain) & No AFB seen & & 2 \\
\hline
\end{tabular}

Table 1:- Results of the initially ordered laboratory investigations 